\title{
Decipherment of the Harappan Script: An Assessment
}

\author{
Ajay Pratap* \\ Department of History, Banaras Hindu University, India \\ *Corresponding author: Ajay Pratap, Department of History, Faculty of Social Sciences, Banaras Hindu University, Uttar Pradesh, India
}

Submission: 眥 January 27, 2018; Published: 眥 June 27, 2018

\begin{abstract}
From Mahadevan [1] pioneering work to Yadav et al. [2] statistical approach to pattern search within the Harappan script, a fact totally overlooked has been that for Harappan Script to be recognized as a script, in which any spoken and or written language may have been inscribed, is that thus far this script has not been found to have been inscribed at what may be called public spaces, in the Harappan Sites excavated thus far. If a script or a likely script is thus not distributed in locations where the encoded messages may be read, then the prospect of this script representing a language of any kind is very weak.
\end{abstract}

\section{Introduction}

In the context of early Indian urbanization, the debate about whether the Harappan corpus of signs and symbols represent a script is a common one. Even if the archaeological evidence points that the Harappan complex of sites does represent a type of urbanization which reached a zenith before eventually declining. However, this paper would like to raise the question if every ancient civilization which is thus urbanized does actually need to have a script, even if quite incontestably they must have a language. It is to the credit of Mahadevan [1] that the entire set of signs and symbols as occurring individually and in conjunction (in their original form) have been identified. However, even if credit is due to him for have separated and identified each unique individual sign and symbol, perhaps his interpretation that this script encodes or represents a Dravidian like language like Malto does not carry very far. The reason is that Malto is a language or rather a dialect spoken by the Paharia people of the Santal Parganas and it does not have a script even today. Perhaps, Mahadevan [1] followed this Dravidianlike language hypothesis since the possibility of an Indo-Aryan dialect existing in the Indus area at this early age is well precluded. However, the mere fact that Dravidian language family is possibly well older in India does not go to prove that the Indus Script such as we know it is a script at all, less so that it represents a Dravidian or any other language. Again, the geographical fact that Mal to is nearest in terms of proximity to the Indus Region does not help very much.

Basing them on Mahadevan's singularly important contribution of having separated every sign and symbol in the corpus of Indus writing, researchers of the Tata Institute of Fundamental Research Yadav et al. [2] have made a very important contribution which is as follows. First of all, Yadav et al. [2] fed into the computer the entire array of signs and symbols and side by side also the actual examples of hypothesized Indus writing, the seals and sealing's etc, into distinct computer databases. Thereafter, a computer program called EBUDS (Extended Basic Unique Database Set) was prepared which would be able to pattern-search the set of signs and symbols to see if any sign or symbol was significantly associated with each other, to the point of a measurable level of statistical significance.

This computer program was then applied to the visual database of the actual examples of Indus writing, on the basis of Mahadevan's concordance, to search for which if any symbol was unique in it's own right, and also to search for significant correlation between one sign and another. After this program was run, Yadav et al. [2] found that indeed there is significant correlation between pairs of some symbols, triples, quadruples and even sets of five symbols. Pursuing further the Indus script as language direction of thought, they have tentatively suggested that this co-occurrence of the same sets of signs and symbols may have phonetic and therefore semantic value. A sort of basic grammar of the basic words of the Indus language.

However, co-occurrence of these signs and symbols may have representational value in realms other than linguistic, such a measurement of weights, quantities, numbers of any kind as well, and not necessarily language per se. Again, until it is identified which language it is which this script represents until then a separation of even phonetic values or phonemes will not have much meaning, semantics will be even more elusive a goal. Therefore, in our view it has not been proved by this method that the signs and symbols of the Indus script necessarily represent a language uniformly spoken in the area. 


\section{Conclusion}

To conclude a few further facts make this enterprise seem more interesting. Possehl [3] while providing important numerical details about just how many signs are there in the corpus of Indus symbols, which precise locations they come from, as well as the materials they are usually found on; also suggests the following:

"The Indus script is found principally on stamp seals, pottery and copper-bronze tablets, tools and weapons. No writing has been found on organic materials like paper, papyrus, leaves, or bark."

In all likelihood, and therefore, most likely these symbols have more to do with quantities than any other thing. A very useful reading here would be Renfrew \& Zubrow [4]. Therefore, based on the current state of research on the subject, in our view it would be difficult to argue that the Harappan script represents a language spoken uni-formally in the larger Harappan area. Not least also because the vast area over which Harappan sites are distributed, some 1.5 million square kilo meters, must also have had a diversity of spoken languages, and the nature of Harappan society at this time, which does not show any appreciable status or ranking differentiation, nor indeed a 'state', precludes the necessity for an 'public' language encoded in a script, with which to for conducting communication simultaneously over this vast habitation area.

\section{References}

1. Mahadevan I (1977) Indus script, texts, concordance and tables. Memoirs of the Archaeological Survey of India, New Delhi, India.

2. Yadav N, Vahia MN, Mahadevan I, Joglekar Hnd (2006) Segmentation of indus texts. Tata Institute of Fundamental Research, Mumbai, India.

3. Possehl GL (2002) The indus civilization: a contemporary perspective. Vistaar Publications, New Delhi, India.

4. Renfrew C, Zubrow EBW (1994) The ancient mind. Elements of cognitive archaeology. New Directions in Archaeology, Cambridge University Press. Cambridge, USA.
Creative Commons Attribution 4.0

International License

For possible submissions Click Here

\section{Submit Article}

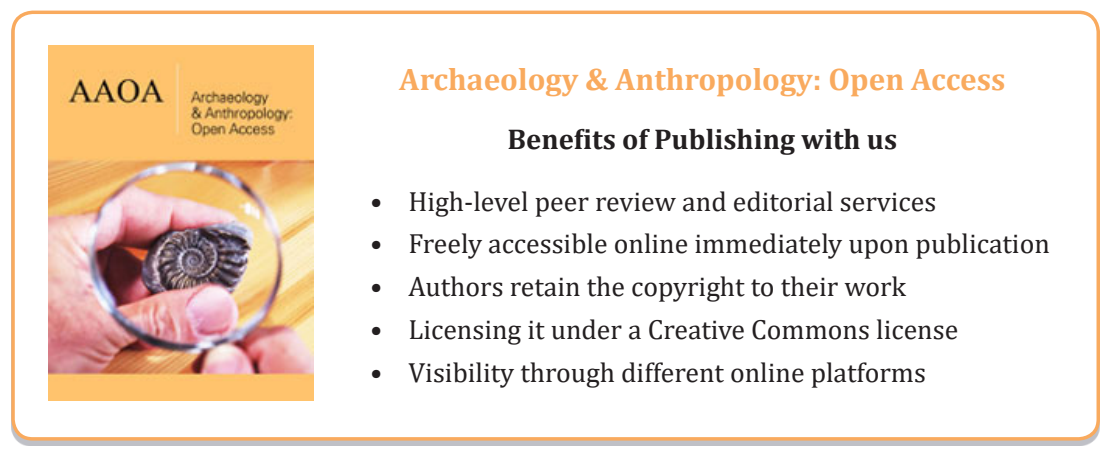

